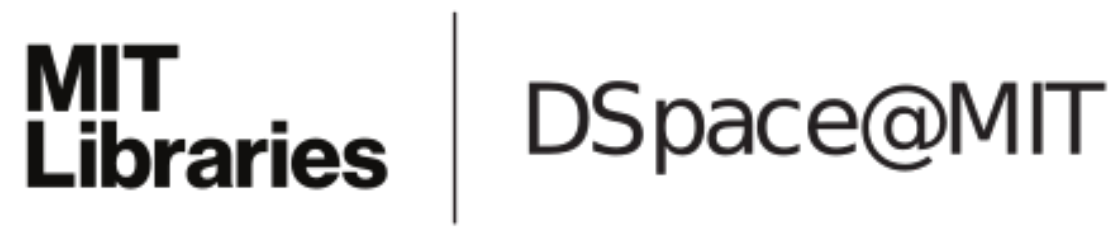

\author{
MIT Open Access Articles
}

\section{Molecular Niobium Precursors in Various Oxidation States: An XAS Case Study}

The MIT Faculty has made this article openly available. Please share how this access benefits you. Your story matters.

Citation: Korzyński, Maciej D., et al. "Molecular Niobium Precursors in Various Oxidation States: an XAS Case Study." Inorganic Chemistry 57, 21 (2018): p. 13998-4004 doi 10.1021/ ACS.INORGCHEM.8B02616 (c)2018 Author(s)

As Published: 10.1021/ACS.INORGCHEM.8B02616

Publisher: American Chemical Society (ACS)

Persistent URL: https://hdl.handle.net/1721.1/126130

Version: Author's final manuscript: final author's manuscript post peer review, without publisher's formatting or copy editing

Terms of Use: Article is made available in accordance with the publisher's policy and may be subject to US copyright law. Please refer to the publisher's site for terms of use. 


\title{
Molecular Niobium Precursors in Various Oxidation States: An XAS Case Study
}

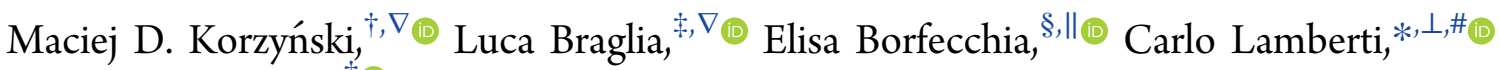 \\ and Mircea Dincă ${ }^{*}+\dot{\dagger}$ (1)
}

${ }^{\dagger}$ Department of Chemistry, Massachusetts Institute of Technology, 77 Massachusetts Avenue, Cambridge, Massachusetts 02139, United States

${ }^{\ddagger}$ CNR-Istituto Officina dei Materiali, TASC Laboratory in Area Science Park - Basovizza, Strada Statale 14 km 163.5 , 34149 Trieste, Italy

${ }^{\S}$ Department of Chemistry, NIS, CrisDi, and INSTM Centre of Reference, University of Turin, Via Quarello 15, I-10135 Torino, Italy

${ }$ Center for Materials Science and Nanotechnology (SMN), Department of Chemistry, University of Oslo, 1033 Blindern, 0315 Oslo, Norway

${ }^{\perp}$ Department of Physics, NIS, CrisDi, Interdepartmental Centers, and INSTM Centre of Reference, University of Turin, Via Giuria 1, I-10125 Torino, Italy

${ }^{{ }^{*}}$ The Smart Materials Research Institute, Southern Federal University, Sladkova Street 178/24, Rostov-on-Don, 344090, Russia

Supporting Information

ABSTRACT: Although X-ray absorption spectroscopy (XAS) has become an indispensable tool in characterization of solidstate materials, it is less of a staple in molecular chemistry of niobium. Scattering X-ray techniques remain relatively unexplored for the systematic study of molecular niobium compounds. Here, we use XAS to probe the niobium environment in commonly used $\mathrm{Nb}$ precursors in $+\mathrm{V},+\mathrm{IV}$, and +III oxidation states. Apart from laying out the guidelines for identification of niobium oxidation states, we correlate our data with density functional theory models to provide further structural insight. Of particular note, we are able to shed light on the nature of the commonly used and catalytically competent $\mathrm{NbCl}_{3}(\mathrm{DME})$, which had not been previously characterized structurally despite its prevalence in $\mathrm{Nb}$ chemistry.

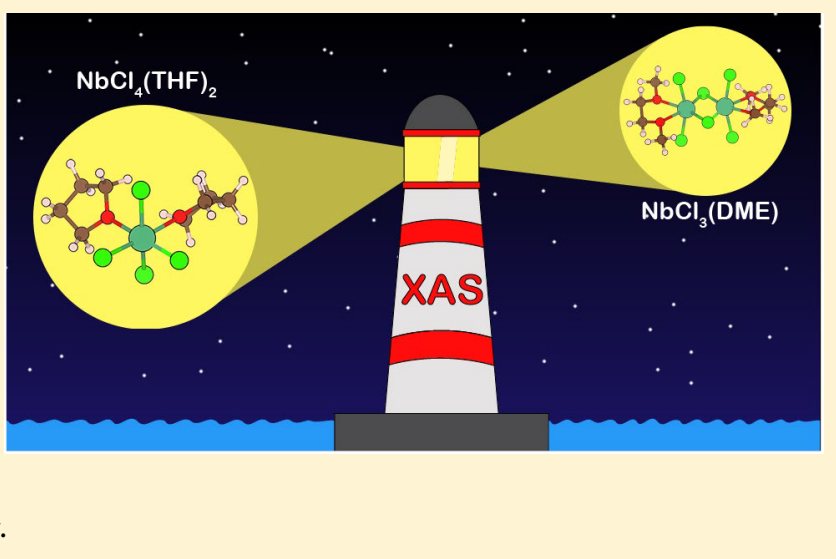

\section{INTRODUCTION}

X-ray absorption spectroscopy (XAS) has become the workhorse characterization technique in solid-state chemistry. ${ }^{1,2}$ XAS spectra comprise two distinct regions: X-ray absorption near edge structure (XANES) and extended X-ray absorption fine structure (EXAFS). Together, they provide crucial information such as oxidation state, symmetry, and coordination environment. ${ }^{3}$ The element specificity of the technique is often the only means available for the investigation of the intimate structure of noncrystalline materials and catalysts. In contrast, molecular chemistry heavily relies on single crystal X-ray diffraction (SCXRD) ${ }^{4}$ for structural insight. SCXRD has obvious advantages, but necessitates the production of single crystals, a nontrivial exercise that often suffers from solubility and/or reactivity issues. $^{5}$

Niobium compounds find utility in material science, ${ }^{6,7}$ fundamental inorganic chemistry, ${ }^{8-12}$ and catalysis. ${ }^{13-16}$ Such compounds must be accessed most often from well-defined molecular $\mathrm{Nb}$ precursors in several oxidation states. Specifically, niobium(V) chloride $\left(\mathrm{NbCl}_{5}\right)$, niobium(IV) chloride tetrahydrofuran complex $\left(\mathrm{NbCl}_{4}(\mathrm{THF})_{2}\right),{ }^{17}$ and niobium(III) chloride dimethoxyethane adduct $\left(\mathrm{NbCl}_{3}(\mathrm{DME})\right)^{18}$ are the most common starting materials for niobium chemistry in their respective oxidation state and even function as catalytically active species themselves. Their formulas, as written above and most often referred to in the literature, are somewhat misleading because only $\mathrm{NbCl}_{5}$ has been structurally characterized and shown to exist itself in the solid state as discrete $\mathrm{Nb}_{2} \mathrm{Cl}_{10}$ dimers. ${ }^{19} \mathrm{~A}$ body of spectroscopic and magnetic studies have suggested that $\mathrm{NbCl}_{4}(\mathrm{THF})_{2}$ exists as a paramagnetic $\left(d^{1}\right)$ monomer with THF molecules arranged in a cis fashion in the solid state with trans geometry observed in solution. ${ }^{20,21}$ For $\mathrm{NbCl}_{3}$ (DME), on the other hand, there is no definitive answer whether this complex exists in monomeric

Received: September 14, 2018 
form, with conflicting reports describing it as either mononuclear $^{22}$ or polymeric. ${ }^{23,24}$ The absence of a single crystal X-ray structure of this compound is most likely a consequence of its high reactivity toward any solvent that it is soluble in. ${ }^{25}$ A structural understanding would be valuable not only for the rational synthesis of other $\mathrm{Nb}$ (III) complexes but also for comprehension of its catalytic performance, such as in $[2+2+2]$ cycloadditions. $^{26-29}$ All precursors would benefit from a rigorous description of their structures, given the current emphasis on precise engineering of materials at the atomic level, from custom materials synthesis to niobium doping.

XAS is well-suited to tackle this challenge. In this contribution, we investigate the coordination environment of these niobium chlorides in $+\mathrm{V},+\mathrm{IV}$, and $+\mathrm{III}$ oxidation states, allowing us to settle a debate regarding the solid-state structure of these molecules aided by correlation with density functional theory (DFT) calculations. This approach, already successfully applied to understand the local structure of metal atoms in zeolites, ${ }^{30}$ metal-organic frameworks, ${ }^{31,32}$ and organometallic complexes, ${ }^{33-36}$ has been named DFT-assisted EXAFS analysis. Using this approach, when different structural models are considered, the selection of the most reliable structural model is based on (i) agreement between experimental and theoretical EXAFS curves ( $R$-factor); (ii) agreement between DFT- and EXAFS-optimized interatomic distances; (iii) error bars associated with the optimized parameters, and (iv) physical meaningfulness of the nonstructural parameters $(\Delta E$ and $\left.\sigma^{2}\right) .^{37}$ Additionally, the XANES region is discussed to benchmark for further studies of oxidation state for new $\mathrm{Nb}$ containing species.

\section{RESULTS AND DISCUSSION}

We began our analysis by looking at $\mathrm{Nb} \mathrm{K}$-edge XANES spectra (Figure 1) of $\mathrm{NbCl}_{5}, \mathrm{NbCl}_{4}(\mathrm{THF})_{2}$, and $\mathrm{NbCl}_{3}$ -

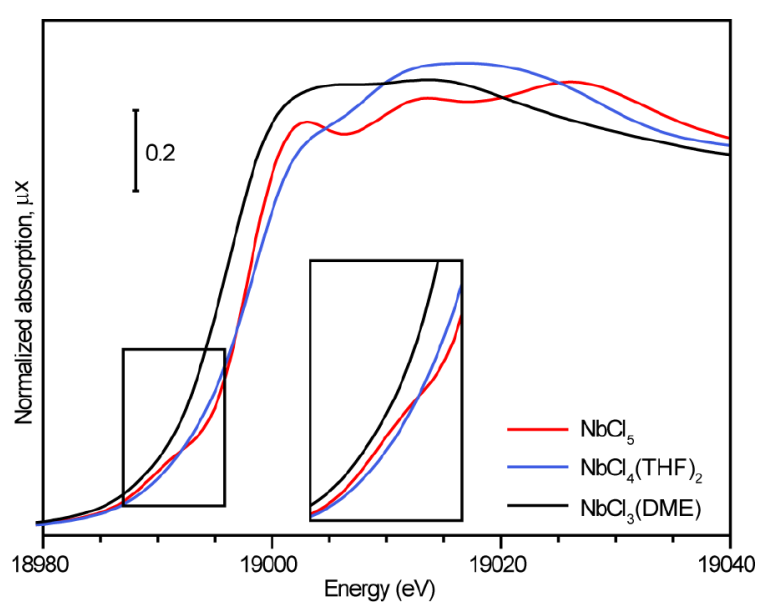

Figure 1. Nb K-edge XANES spectra of the investigated species.

(DME), which allow us to assign the oxidation state of niobium in each of these compounds as $+\mathrm{V},+\mathrm{IV}$, and +III, respectively. This assignment is based on the qualitative description of the XANES spectra supported by the literature. ${ }^{38} \mathrm{~A}$ decrease in the edge energy can be observed for $\mathrm{NbCl}_{3}(\mathrm{DME})(18995.6 \mathrm{eV})$ compared to that of the higher valent $\mathrm{Nb}(\mathrm{IV})$ and $\mathrm{Nb}(\mathrm{V})$ precursors $(18997.8 \mathrm{eV})$. This red shift is in line with the expected increase of the electron binding energy in higher oxidation states. In the spectrum of niobium $(\mathrm{V})$ chloride, a weak pre-edge shoulder centered at $18990 \mathrm{eV}$ can be observed. This feature is related to an electronic transition from the 1 s-orbital to the $4 \mathrm{~d}$-orbital manifold and has already been observed in niobium $(\mathrm{V})$ oxide $\left(\mathrm{Nb}_{2} \mathrm{O}_{5}\right){ }^{39}$ A systematic study ${ }^{38}$ of minerals containing $\mathrm{Nb}^{0}$, $\mathrm{Nb}^{2+}, \mathrm{Nb}^{4+}$, and $\mathrm{Nb}^{5+}$ ions utilizing $\mathrm{Nb}$ K-edge XANES has shown that the pre-edge feature is typically only seen for +5 and mixed valent $+4 /+5$ and is absent for other oxidation states irrespective of geometry. Our analysis confirms that this trend also holds for $\mathrm{Nb}^{3+}$ species. All three chlorides show strong absorption peaks at approximately 19003 and 19013 eV. $\mathrm{NbCl}_{4}(\mathrm{THF})_{2}$ and $\mathrm{NbCl}_{5}$ distinguish themselves by the presence of an additional feature at 19018 and $19026 \mathrm{eV}$, respectively, which is due to low energy scattering resonances of photoelectrons by neighboring atoms.

The obtained EXAFS data (Figure S3) have an excellent signal/noise ratio up to $k=18 \AA^{-1}$, which allowed us to elucidate the structure of the investigated compounds. The strategy that was adopted relied on the optimization of the possible structural models using DFT. These models served as starting points for the fitting of the EXAFS signal. We began our analysis with the niobium(V) chloride, which was previously characterized by SCXRD studies, ${ }^{19}$ in order to validate our approach to data analysis. The DFT optimized model (Figure 2a) matched the reported crystal structure well a)

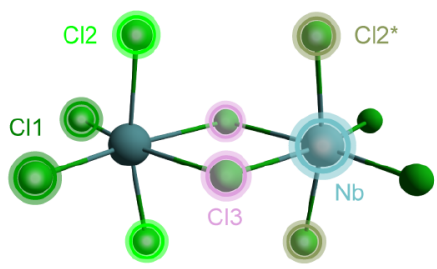

b)
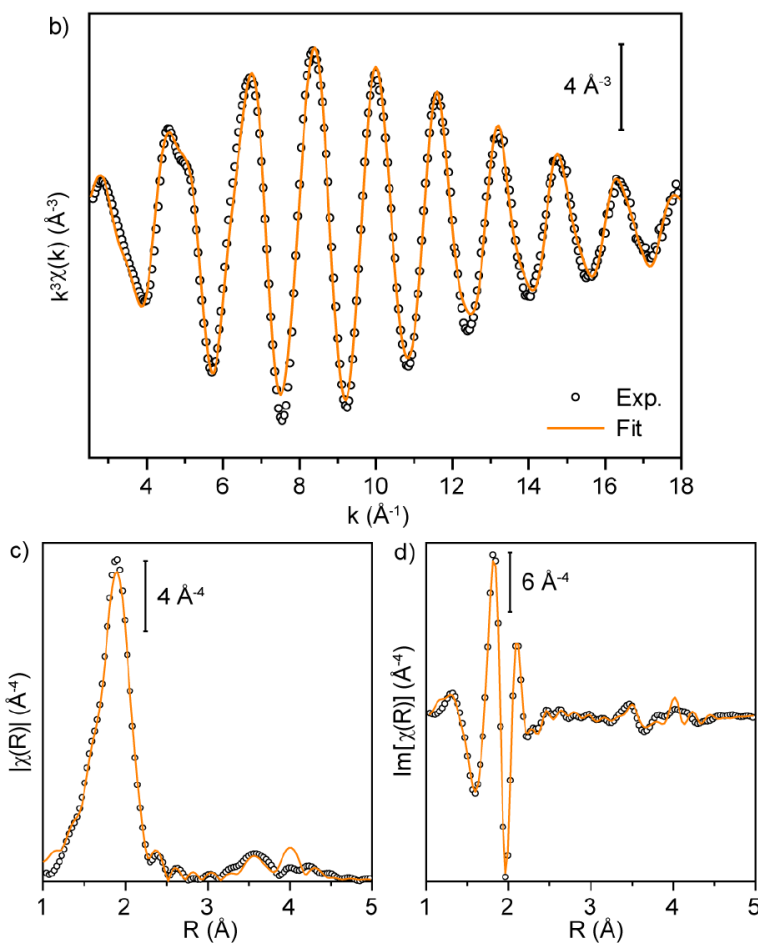

Figure 2. (a) Optimized DFT model of $\mathrm{NbCl}_{5}$. (b) $k^{3}$-weighted EXAFS signal, and corresponding modulus (c) and imaginary (d) parts of the phase uncorrected FT of the experimental and best fit for $\mathrm{NbCl}_{5}$. 
a)

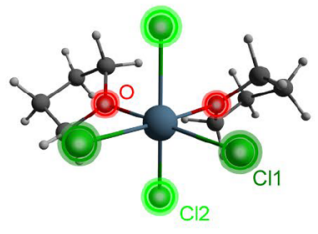

b)

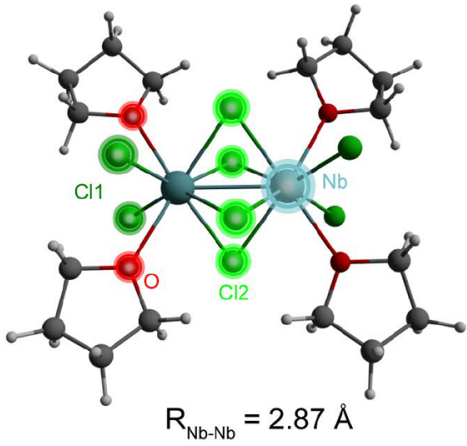

c)

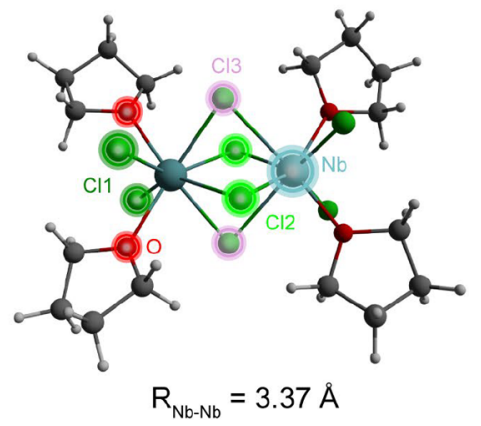

Figure 3. DFT-optimized structures for $\mathrm{NbCl}_{4}(\mathrm{THF})_{2}$ as (a) monomer, (b) singlet dimer, and (c) triplet dimer.

(Table S2). For this and forthcoming analyses, the amplitude reduction factor ${ }^{40}\left(S_{0}{ }^{2}\right)$ was fixed to 1 . To reduce the number of independent parameters optimized in the fit, the single scattering (SS) and the multiple scattering (MS) paths were defined geometrically (for additional details, see the Supporting Information). We defined two Debye-Waller factors $\sigma_{\mathrm{Cl1}, 2,2 *}^{2}$ and $\sigma_{\mathrm{Cl} 3}^{2}$ to account for a difference between terminal and bridging chlorides, respectively. The parameter correlation was monitored to avoid values bigger than 0.8 in absolute value. The obtained fit (for parameters, see Table S1), using the $\mathrm{NbCl}_{5}$ DFT-optimized model, reproduces our experimental data well (Figure $2 \mathrm{~b}-\mathrm{d}$ ). Both $\mathrm{Nb}-\mathrm{Nb}$ and $\mathrm{Nb}-\mathrm{Cl}$ distances are in good agreement with both the DFT calculations and SCXRD data (Table S2). Interestingly, in the best-fit set of parameters, the bridging chlorides seem to have a higher Debye-Waller factor than terminal ones. This may be related to peculiar vibration modes of the structure. Having established a successful data analysis methodology on $\mathrm{NbCl}_{5}$, we next shifted our attention to the other niobium complexes, whose structure could not be determined by SCXRD. In all cases, the EXAFS fit was performed using an isotropic expansion coefficient ${ }^{41-44}$ to reproduce the higher shell contributions (see the Supporting Information).

For the niobium(IV) chloride THF adduct, both monomeric and dimeric structures were considered. As $\mathrm{NbCl}_{4}$ $(\mathrm{MeCN})_{2}$ is a related, structurally characterized monomeric compound, $^{45}$ we used it as a template for DFT calculations (Figure 3a). A less common, but prevalent, type of structure for " $\mathrm{NbCl}_{4} \mathrm{~L}_{2}$ " stoichiometry (where $\mathrm{L}$ is typically a monodentate phosphine) is a dimeric $\left[\mathrm{NbCl}_{2} \mathrm{~L}_{2}\right]_{2}(\mu-\mathrm{Cl})_{4}$ face-sharing double square antiprism. ${ }^{46,47}$ We have optimized the structure of the analogous dimer for $\mathrm{NbCl}_{4}(\mathrm{THF})_{2}$ in two spin states, singlet and triplet (Figure $3 b, c$, respectively), as expected in spin-symmetric systems arising from two $\mathrm{d}^{1}$ centers. The most striking differences between these two spin states is the considerable difference in the $\mathrm{Nb}-\mathrm{Nb}$ distances (2.87 $\AA$ for singlet and $3.37 \AA$ for triplet) concomitant with the formal single bond between the two metal centers in the case of the $S=0$ system. Additionally, the singlet structure exhibits bridging chlorides equidistant from both $\mathrm{Nb}$ centers, as opposed to the triplet structure, which has two independent sets of $\mathrm{Nb}-(\mu-\mathrm{Cl})$ distances.

An initial look at the correspondence of the obtained EXAFS signal and the fit (Figure 4) obtained using the dimeric model in the triplet state shows a poor match with an $R$-factor of 0.2 and unreasonably high $\Delta E$ value $(15 \pm 2 \mathrm{eV})$. Additionally, the $\sigma_{O}^{2}$ and $\sigma^{2}$ are unphysically low $\left(0.0003 \pm 0.0006 \AA^{2}\right.$ and $0.0004 \pm 0.0031 \AA^{2}$ ). While both fits for the monomeric
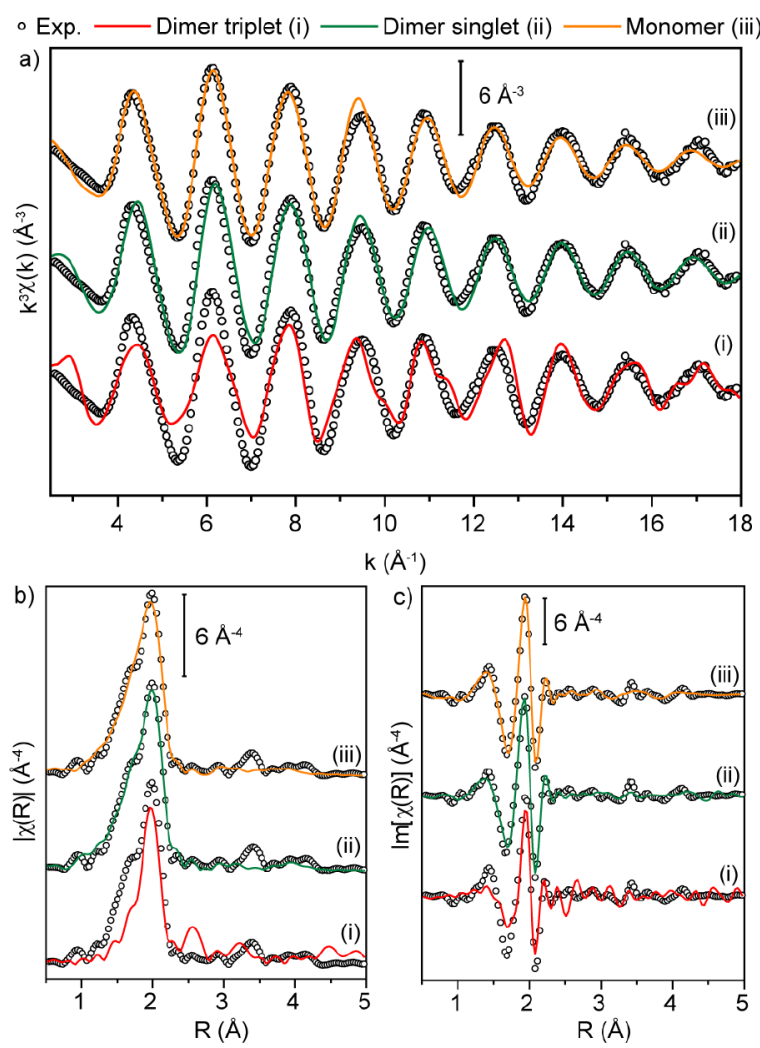

Figure 4. (a) $k^{3}$-weighted EXAFS functions. Corresponding modulus (b) and imaginary (c) part of the phase uncorrected FT. The experimental data and the best fits for the three different $\mathrm{NbCl}_{4}(\mathrm{THF})_{2}$ models.

structure and dimer in singlet configuration reproduce the experimental spectrum well up to $3 \AA$, some of the minor features beyond the first coordination shell are difficult to be reproduced. A possible explanation involves contribution from neighboring molecules in the lattice, not factored in our nonperiodic model. From the comparison of the EXAFS analysis obtained using these two models, several observations undermine the feasibility of the dimeric structure. An unexpectedly large compression of the $\mathrm{Nb}-\mathrm{Nb}$ distance occurs $(2.28 \pm 0.02 \AA)$ compared to the DFT optimized model (Table $\mathrm{S} 4)$. The same applies to the $\mathrm{Nb}-(\mu-\mathrm{Cl})$ distances, which are also short compared to both the DFT model as well as the published distances for other face-sharing double square antiprismatic structures. ${ }^{48}$ Very large fitting errors for $\mathrm{Nb}-\mathrm{Cl}$ and $\mathrm{Nb}-\mathrm{O}$ bond distances underscore further inconsistencies with this model (Table S3). In light of the presented data, our 
a)

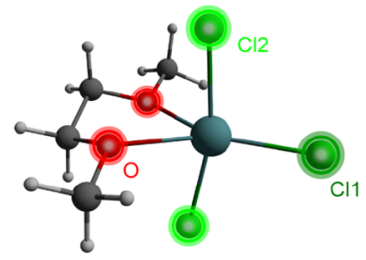

c)

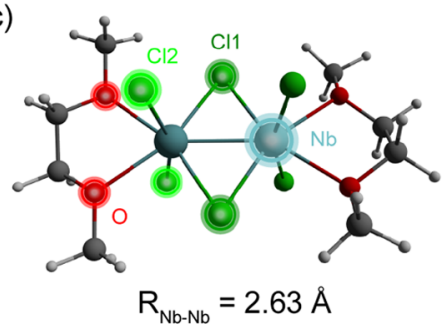

d)

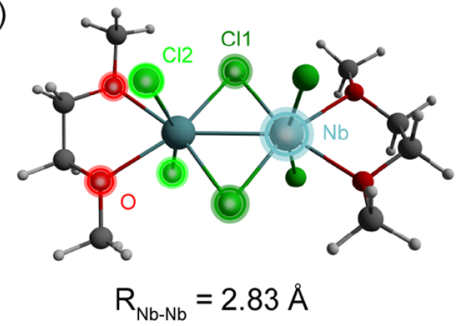

b)

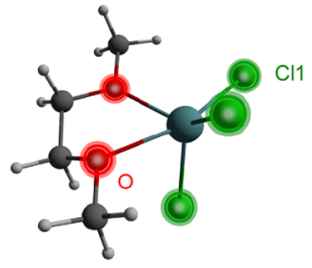

e)

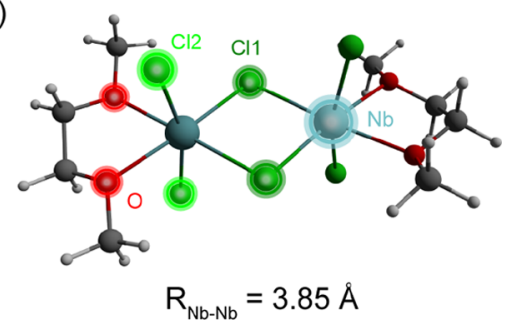

Figure 5. DFT-optimized structures for $\mathrm{NbCl}_{3}(\mathrm{DME})$ as (a) singlet monomer, (b) triplet monomer, (c) singlet dimer, (d) triplet dimer, and (e) quintet dimer.

analysis supports the existence of $\mathrm{NbCl}_{4}(\mathrm{THF})_{2}$ in the solid state as a monomeric pseudo-octahedron with one unpaired electron contributing to its magnetic moment.

Finally, we investigated niobium(III) chloride dimethoxyethane complex, which has previously been described as both a monomer and a polymer, with no definitive experimental evidence distinguishing these possibilities to our knowledge. As a monomer, the $\mathrm{d}^{2}$ niobium center could exhibit either singlet or triplet character (Figure 5a,b, respectively). Dimeric structures are also well-known for several $\mathrm{Nb}$ (III) halide complexes ligated with $\mathrm{N}^{49,50} \mathrm{P},{ }^{49,51,52}$ and $\mathrm{S}^{53,54}$ donors. Thus, we have also optimized edge-sharing bioctahedral structures in singlet, triplet, and quintet spin states (Figure $5 \mathrm{c}-\mathrm{e})$ based on the known crystal structures with bound acetonitrile. The most pronounced consequence of varying the spin state is expectedly the change in the $\mathrm{Nb}-\mathrm{Nb}$ distance and the formal intermetallic bond order. Structures involving bridging DME ligands were excluded due to the fact that such coordination has only been observed in the case of the smaller bite angle chelating ligands such as methylenebis(phosphine)s. ${ }^{55}$

Attempts to fit the EXAFS data using the optimized models (Figure 6) showed that both singlet and triplet monomeric models reproduced the experimental data poorly, as evidenced by high $R$-factors (Table S5). Moreover, the fit for the monomer in the singlet state had an unphysically high $\sigma_{\mathrm{O}}^{2}$ parameter $\left(0.01 \AA^{2}\right)$ and large errors for $\sigma_{\mathrm{O}}^{2}$ and for both $\mathrm{Nb}-$ $\mathrm{O}$ and $\mathrm{Nb}-\mathrm{Cl}_{1,2}$ interatomic distances $( \pm 0.1$ and $\pm 0.2 \AA$, respectively). Similar instabilities in the fit for the monomer in the triplet state could be observed: large errors for $\alpha$ and $\sigma^{2}$ ( \pm 102 and $\pm 120 \AA^{2}$, respectively) and unphysical, negative $\sigma_{\mathrm{O}}^{2}$. The quintet dimeric structure also reproduced the experimental spectrum poorly ( $R$-factor is 0.05$)$ with a very low value of $\sigma_{\mathrm{Cl}}^{2}\left(0.0007 \pm 0.0007 \AA^{2}\right)$ and high $\sigma_{\mathrm{O}}^{2}(0.01 \pm$ $0.02 \AA^{2}$ ).

We found that fits to the dimeric models in both the single and triplet states were a much better match with the experimental data. On the basis of the fit parameters, the singlet dimeric structure is more probable as evidenced by closer correspondence of the calculated $\mathrm{Nb}-\mathrm{Nb}$ distances with the ones obtained from the fitting procedure (Table S6). The obtained distance $(2.700 \AA)$ also matches those of other singlet dimeric niobium species. ${ }^{48}$ Notably, during the fitting for the
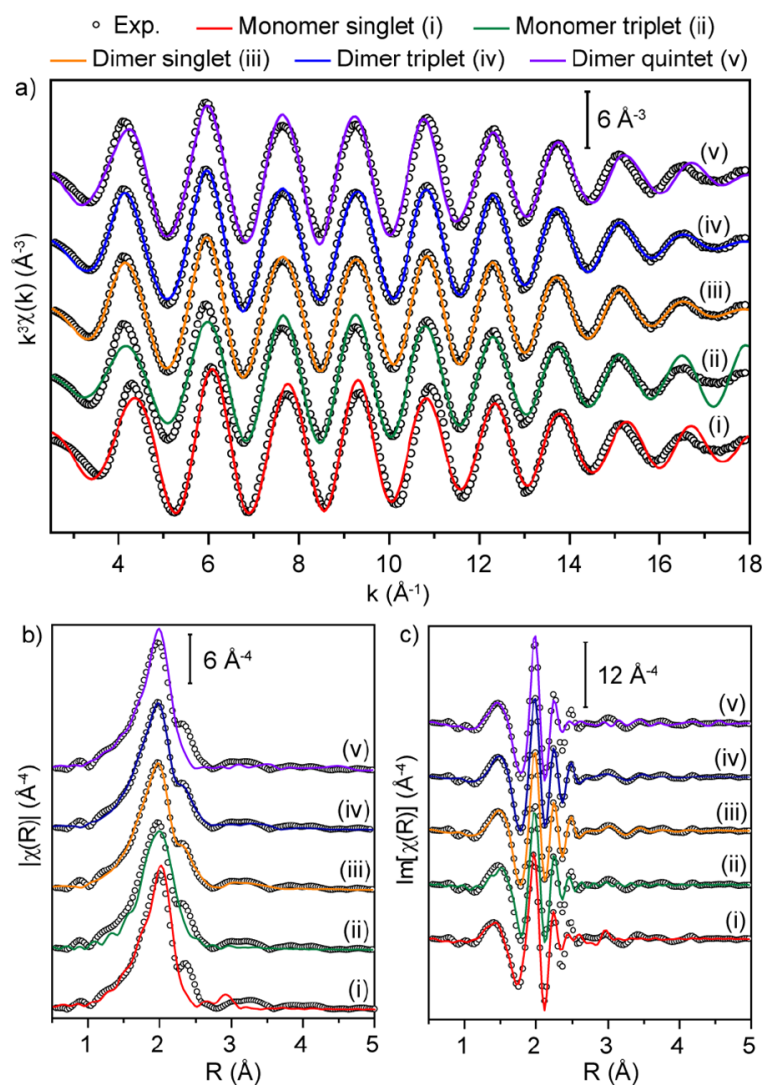

Figure 6. (a) $k^{3}$-weighted EXAFS functions. Corresponding modulus (b) and imaginary (c) part of the phase uncorrected FT. The experimental data and the best fits for the five different $\mathrm{NbCl}_{3}(\mathrm{DME})$ models.

triplet model, the $\mathrm{Nb}-\mathrm{Nb}$ distance underwent contraction more in line with the one obtained from the optimization of the singlet structure. Additionally, the $\sigma_{\mathrm{Cl}}^{2}$ value for the triplet configuration is unreliably low $\left(0.0011 \pm 0.0003 \AA^{2}\right)$, further disfavoring the triplet state.

To further confirm the singlet spin state of the $\left[\mathrm{NbCl}_{2}\right.$ $(\mathrm{DME})]_{2}(\mu-\mathrm{Cl})_{2}$ dimer, we compared its computed Gibbs free energy at $298.15 \mathrm{~K}$ with that of the dimer in the triplet state. Although the singlet configuration was indeed lower in energy, it was preferred by only $0.7 \mathrm{kcal} / \mathrm{mol}$, a difference too small to 
serve as incontrovertible proof for any of these two electronic configurations. Confirmation of the magnetic ground state came instead from vibrating sample magnetometry (VSM) measurements on $\left[\mathrm{NbCl}_{2}(\mathrm{DME})\right]_{2}(\mu-\mathrm{Cl})_{2}$ and $\mathrm{NbCl}_{4}(\mathrm{THF})_{2}$ (Figure S4). For the latter, the extracted effective magnetic moment $\left(\mu_{\text {eff }}=1.73\right.$ at $\left.274 \mathrm{~K}\right)$ is in line with the expectations for a $\mathrm{d}^{1}$ system. The same measurement performed on $\left[\mathrm{NbCl}_{2}(\mathrm{DME})\right]_{2}(\mu-\mathrm{Cl})_{2}$ showed essentially diamagnetic behavior in line with $S=0$ configuration. The combination of all of these techniques has led us to propose a reformulation of $\mathrm{NbCl}_{3}(\mathrm{DME})$ as $\left[\mathrm{NbCl}_{2}(\mathrm{DME})\right]_{2}(\mu-\mathrm{Cl})_{2}$ in the solid state.

\section{CONCLUSION}

In this contribution, we investigated simple niobium halide precursors commonly used in inorganic synthesis and catalysis. As $\mathrm{NbCl}_{4}(\mathrm{THF})_{2}$ and $\mathrm{NbCl}_{3}(\mathrm{DME})$ have proven difficult to analyze via single crystal X-ray diffractometry, we utilized DFTassisted EXAFS analysis to gain insight into their solid-state structure. This technique, still underutilized in the molecular inorganic chemistry of niobium, allowed us to confirm the notion that the niobium(IV) chloride tetrahydrofuran adduct is monomeric in the solid state. It has also allowed us to establish that the common and commercially available niobium(III) chloride dimethoxyethane complex does not exist in a monomeric form as previously assumed, but as a dimer akin to other niobium(III) halides ligated with $\mathrm{N}$ and $\mathrm{P}$ donors. XANES spectroscopy has been used to confirm the valence state of $\mathrm{Nb}$.

\section{ASSOCIATED CONTENT}

\section{S Supporting Information}

The Supporting Information is available free of charge on the ACS Publications website at DOI: 10.1021/acs.inorgchem.8b02616.

Experimental details, computational methods, detailed list of EXAFS fit parameters, magnetic measurement data, and $x y z$ coordinates for the optimized structures (PDF)

\section{AUTHOR INFORMATION}

\section{Corresponding Authors}

*E-mail: carlo.lamberti@unito.it (C.L.).

*E-mail: mdinca@mit.edu (M.D.).

\section{ORCID $\odot$}

Maciej D. Korzyński: 0000-0002-6577-1821

Luca Braglia: 0000-0003-0796-3670

Elisa Borfecchia: 0000-0001-8374-8329

Carlo Lamberti: 0000-0001-8004-2312

Mircea Dincă: 0000-0002-1262-1264

\section{Author Contributions}

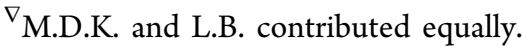

\section{Funding}

All synthetic work was supported by the National Science Foundation through a CAREER award to M.D. (DMR1452612). C.L. thanks the Russian Ministry of Education and Science for support (megagrant of the Russian Federation Government No. 14.Y26.31.0001).

\section{Notes}

The authors declare no competing financial interest.

\section{ACKNOWLEDGMENTS}

The authors would like to gratefully acknowledge Prof. Christopher C. Cummins for useful comments, Dr. Giovanni Agostini and Dr. Kirill A. Lomachenko for their help with XAS data collection at the BM23 beamline ${ }^{56}$ of the ESRF synchrotron, and Dr. Wesley J. Transue for discussions regarding the computational methods.

\section{REFERENCES}

(1) Bordiga, S.; Bonino, F.; Lillerud, K. P.; Lamberti, C. X-Ray Absorption Spectroscopies: Useful Tools to Understand Metallorganic Frameworks Structure and Reactivity. Chem. Soc. Rev. 2010, 39, 4885-4927.

(2) Bordiga, S.; Groppo, E.; Agostini, G.; van Bokhoven, J. A.; Lamberti, C. Reactivity of Surface Species in Heterogeneous Catalysts Probed by In Situ X-Ray Absorption Techniques. Chem. Rev. 2013, 113, 1736-1850.

(3) X-Ray Absorption and X-Ray Emission Spectroscopy; Van Bokhoven, J. A., Lamberti, C., Eds.; John Wiley \& Sons, Ltd.: Chichester, U.K., 2016.

(4) Baur, W. H. One Hundred Years of Inorganic Crystal Chemistry - a Personal View. Crystallogr. Rev. 2014, 20, 64-116.

(5) Garino, C.; Borfecchia, E.; Gobetto, R.; van Bokhoven, J. A.; Lamberti, C. Determination of the Electronic and Structural Configuration of Coordination Compounds by Synchrotron-Radiation Techniques. Coord. Chem. Rev. 2014, 277-278, 130-186.

(6) Hubert-Pfalzgraf, L. G. Niobium \& Tantalum: Inorganic \& Coordination Chemistry. In Encyclopedia of Inorganic Chemistry; John Wiley \& Sons, Ltd.: Chichester, U.K., 2006.

(7) Tarselli, M. A. Subtle Niobium. Nat. Chem. 2015, 7, 180-180.

(8) Fryzuk, M. D.; Kozak, C. M.; Bowdridge, M. R.; Patrick, B. O.; Rettig, S. J. Nitride Formation by Thermolysis of a Kinetically Stable Niobium Dinitrogen Complex. J. Am. Chem. Soc. 2002, 124, 83898397.

(9) Cossairt, B. M.; Cummins, C. C. Shuttling $\mathrm{P}_{3}$ from Niobium to Rhodium: The Synthesis and Use of $\mathrm{Ph}_{3} \mathrm{SnP}_{3}\left(\mathrm{C}_{6} \mathrm{H}_{8}\right)$ as a $\mathrm{P}_{3}{ }^{-}$ Synthon. Angew. Chem., Int. Ed. 2010, 49, 1595-1598.

(10) Kurogi, T.; Carroll, P. J.; Mindiola, D. J. A Terminally Bound Niobium Methylidyne. J. Am. Chem. Soc. 2016, 138, 4306-4309.

(11) Culcu, G.; Iovan, D. A.; Krogman, J. P.; Wilding, M. J. T.; Bezpalko, M. W.; Foxman, B. M.; Thomas, C. M. Heterobimetallic Complexes Comprised of $\mathrm{Nb}$ and $\mathrm{Fe}$ : Isolation of a Coordinatively Unsaturated $\mathrm{Nb}^{\mathrm{III}} / \mathrm{Fe}^{0}$ Bimetallic Complex Featuring a $\mathrm{Nb} \equiv \mathrm{Fe}$ Triple Bond. J. Am. Chem. Soc. 2017, 139, 9627-9636.

(12) Bortoluzzi, M.; Ferretti, E.; Marchetti, F.; Pampaloni, G.; Pinzino, C.; Zacchini, S. Coordination Compounds of Niobium(IV) Oxide Dihalides Including the Synthesis and the Crystallographic Characterization of NHC Complexes. Inorg. Chem. 2016, 55, 41734182

(13) Tanabe, K.; Okazaki, S. Various Reactions Catalyzed by Niobium Compounds and Materials. Appl. Catal., A 1995, 133, 191218.

(14) Tanabe, K. Catalytic Application of Niobium Compounds. Catal. Today 2003, 78, 65-77.

(15) Luisa Marin, M.; Hallett-Tapley, G. L.; Impellizzeri, S.; Fasciani, C.; Simoncelli, S.; Netto-Ferreira, J. C.; Scaiano, J. C. Synthesis, Acid Properties and Catalysis by Niobium Oxide Nanostructured Materials. Catal. Sci. Technol. 2014, 4, 3044-3052.

(16) Satoh, Y.; Obora, Y. Niobium Complexes in Organic Transformations: From Stoichiometric Reactions to Catalytic $[2+$ 2+2] Cycloaddition Reactions. Eur. J. Org. Chem. 2015, 2015, 50415054.

(17) Herndon, J. W. Niobium(IV) Chloride. In Encyclopedia of Reagents for Organic Synthesis; John Wiley \& Sons, Ltd.: Chichester, U.K., 2001; Vol. 4, p 3152.

(18) Roskamp, C. A.; Roskamp, E. J. Trichloro(1,2Dimethoxyethane)Niobium. In Encyclopedia of Reagents for Organic 
Synthesis; John Wiley \& Sons, Ltd.: Chichester, U.K., 2001; Vol. 3, pp $2-3$.

(19) Cotton, F. A.; Kibala, P. A.; Matusz, M.; Sandor, R. B. W. Structure of the Second Polymorph of Niobium Pentachloride. Acta Crystallogr., Sect. C: Cryst. Struct. Commun. 1991, 47, 2435-2437.

(20) Fowles, G. W. A.; Tidmarsh, D. J.; Walton, R. A. A Study of the Stereochemistry and Magnetic and Spectral Properties of Coordination Compounds of the Niobium(IV) and Tantalum(IV) Chlorides and Bromides and of the Complex Anions $\mathrm{NbCl}_{6}{ }^{2-}$ and $\mathrm{NbBr}_{6}{ }^{2-}$. Inorg. Chem. 1969, 8, 631-638.

(21) Johnson, D. P.; Bereman, R. D. ESR Investigations of Complexes of Niobium(IV) Chloride with Oxygen Donors. J. Inorg. Nucl. Chem. 1972, 34, 2957-2959.

(22) Matsuura, M.; Fujihara, T.; Kakeya, M.; Sugaya, T.; Nagasawa, A. Dinuclear Niobium(III) and Tantalum(III) Complexes with Thioether and Selenoether Ligands $\left[\left\{\mathrm{M}^{\mathrm{III}} \mathrm{X}_{2}(\mathrm{~L})\right\}_{2}(\mu \text {-X })_{2}(\mu\right.$-L) $](\mathrm{M}$ $\left.=\mathrm{Nb}, \mathrm{Ta} ; \mathrm{X}=\mathrm{Cl}, \mathrm{Br} ; \mathrm{L}=\mathrm{R}_{2} \mathrm{~S}, \mathrm{R}_{2} \mathrm{Se}\right)$ : Syntheses, Structures, and the Optimal Conditions and the Mechanism of the Catalysis for Regioselective cyclotrimerization of alkynes. J. Organomet. Chem. 2013, 745-746, 288-298.

(23) Antiñolo, A.; Carrillo-Hermosilla, F.; Díez-Barra, E.; Fernández-Baeza, J.; Lara-Sánchez, A.; Otero, A.; Tejeda, J. Phosphorus Ylide-Containing Niobium Complexes: Preparation and Characterization of Homo- and Heteronuclear Compounds with an $\alpha$-Keto Ylide Ligand. J. Organomet. Chem. 1998, 570, 97-105.

(24) Oulié, P.; Bréfuel, N.; Vendier, L.; Duhayon, C.; Etienne, M. A New Way to Scorpionate Niobium Complexes: Terminal Alkyne, Imido, and Oxo Complexes and the Rearrangement of $\alpha$-Agostic Ethyl Complexes. Organometallics 2005, 24, 4306-4314.

(25) Roskamp, E. J.; Pedersen, S. F. The First Practical Niobium(III) Reagent in Organic Synthesis. A Convenient Route to 2-Amino Alcohols via the Coupling of Imines with Aldehydes or Ketones Promoted by $\mathrm{NbCl}_{3}$ (DME). J. Am. Chem. Soc. 1987, 109, $6551-6553$

(26) Obora, Y.; Takeshita, K.; Ishii, Y. $\mathrm{NbCl}_{3}$-Catalyzed $[2+2+2]$ Intermolecular Cycloaddition of Alkynes and Alkenes to 1,3Cyclohexadiene Derivatives. Org. Biomol. Chem. 2009, 7, 428-431.

(27) Obora, Y.; Satoh, Y.; Ishii, Y. $\mathrm{NbCl}_{3}$-Catalyzed Intermolecular $[2+2+2]$ Cycloaddition of Alkynes and $\alpha, \omega$-Dienes: Highly Chemoand Regioselective Formation of 5- $\omega$-Alkenyl-1,4-Substituted-1,3Cyclohexadiene Derivatives. J. Org. Chem. 2010, 75, 6046-6049.

(28) Satoh, Y.; Obora, Y. $\mathrm{NbCl}_{3}$-Catalyzed Three-Component $[2+$ $2+2]$ Cycloaddition Reaction of Terminal Alkynes, Internal Alkynes, and Alkenes to 1,3,4,5-Tetrasubstituted 1,3-Cyclohexadienes. Org. Lett. 2011, 13, 2568-2571.

(29) Simon, C.; Amatore, M.; Aubert, C.; Petit, M. Mild NiobiumCatalyzed $[2+2+2]$ Cycloaddition of Sila-Triynes: Easy Access to Polysubstituted Benzosilacyclobutenes. Org. Lett. 2015, 17, 844-847.

(30) Borfecchia, E.; Lomachenko, K. A.; Giordanino, F.; Falsig, H.; Beato, P.; Soldatov, A. V.; Bordiga, S.; Lamberti, C. Revisiting the Nature of $\mathrm{Cu}$ Sites in the Activated Cu-SSZ-13 Catalyst for SCR Reaction. Chem. Sci. 2015, 6, 548-563.

(31) Valenzano, L.; Civalleri, B.; Chavan, S.; Bordiga, S.; Nilsen, M. H.; Jakobsen, S.; Lillerud, K. P.; Lamberti, C. Disclosing the Complex Structure of UiO-66 Metal Organic Framework: A Synergic Combination of Experiment and Theory. Chem. Mater. 2011, 23, $1700-1718$.

(32) Chavan, S.; Vitillo, J. G.; Gianolio, D.; Zavorotynska, O.; Civalleri, B.; Jakobsen, S.; Nilsen, M. H.; Valenzano, L.; Lamberti, C.; Lillerud, K. P.; Bordiga, S. $\mathrm{H}_{2}$ Storage in Isostructural UiO-67 and UiO-66 MOFs. Phys. Chem. Chem. Phys. 2012, 14, 1614-1626.

(33) Salassa, L.; Garino, C.; Salassa, G.; Nervi, C.; Gobetto, R.; Lamberti, C.; Gianolio, D.; Bizzarri, R.; Sadler, P. J. Ligand-Selective Photodissociation from $\left[\mathrm{Ru}(\mathrm{bpy})(4 \mathrm{AP})_{4}\right]^{2+}$ : A Spectroscopic and Computational Study. Inorg. Chem. 2009, 48, 1469-1481.

(34) Salassa, L.; Ruiu, T.; Garino, C.; Pizarro, A. M.; Bardelli, F.; Gianolio, D.; Westendorf, A.; Bednarski, P. J.; Lamberti, C.; Gobetto, R.; Sadler, P. J. EXAFS, DFT, Light-Induced Nucleobase Binding, and
Cytotoxicity of the Photoactive Complex cis-[Ru(bpy $\left.)_{2}(\mathrm{CO}) \mathrm{Cl}\right]^{+}$. Organometallics 2010, 29, 6703-6710.

(35) Estephane, J.; Groppo, E.; Vitillo, J. G.; Damin, A.; Gianolio, D.; Lamberti, C.; Bordiga, S.; Quadrelli, E. A.; Basset, J. M.; Kervern, G.; Emsley, L.; Pintacuda, G.; Zecchina, A. A Multitechnique Approach to Spin-Flips for $\mathrm{Cp}_{2} \mathrm{Cr}$ (II) Chemistry in Confined State. J. Phys. Chem. C 2010, 114, 4451-4458.

(36) Borfecchia, E.; Garino, C.; Salassa, L.; Ruiu, T.; Gianolio, D.; Zhang, X.; Attenkofer, K.; Chen, L. X.; Gobetto, R.; Sadler, P. J.; Lamberti, C. X-Ray Transient Absorption Structural Characterization of the ${ }^{3}$ MLCT Triplet Excited State of cis- $\left[\mathrm{Ru}(\mathrm{bpy})_{2}(\mathrm{py})_{2}\right]^{2+}$. Dalt. Trans. 2013, 42, 6564-6571.

(37) Estephane, J.; Groppo, E.; Damin, A.; Vitillo, J. G.; Gianolio, D.; Lamberti, C.; Bordiga, S.; Prestipino, C.; Nikitenko, S.; Quadrelli, E. A.; Taoufik, M.; Basset, J. M.; Zecchina, A. Structure and Enhanced Reactivity of Chromocene Carbonyl Confined inside Cavities of $\mathrm{NaY}$ Zeolite. J. Phys. Chem. C 2009, 113, 7305-7315.

(38) Martin, R. F.; Wülser, P.-A. Niobium and Tantalum in Minerals: Siderophile, Chalcophile or Lithophile, and Polyvalent. J. Geochem. Explor. 2014, 147 (Part A), 16-25.

(39) Antonio, M. R.; Song, I.; Yamada, H. Coordination and Valence of Niobium in $\mathrm{TiO}_{2}-\mathrm{NbO}_{2}$ Solid Solutions through X-Ray Absorption Spectroscopy. J. Solid State Chem. 1991, 93, 183-192.

(40) Kas, J. J.; Sorini, A. P.; Prange, M. P.; Cambell, L. W.; Soininen, J. A.; Rehr, J. J. Many-Pole Model of Inelastic Losses in X-ray Absorption Spectra. Phys. Rev. B: Condens. Matter Mater. Phys. 2007, $76,195116$.

(41) Lamberti, C.; Groppo, E.; Prestipino, C.; Casassa, S.; Ferrari, A. M.; Pisani, C.; Giovanardi, C.; Luches, P.; Valeri, S.; Boscherini, F. Oxide/Metal Interface Distance and Epitaxial Strain in the $\mathrm{NiO} /$ $\mathrm{Ag}(001)$ System. Phys. Rev. Lett. 2003, 91, 046101.

(42) Groppo, E.; Prestipino, C.; Lamberti, C.; Luches, P.; Giovanardi, C.; Boscherini, F. Growth of $\mathrm{NiO}$ on $\mathrm{Ag}(001)$ : Atomic Environment, Strain, and Interface Relaxations Studied by Polarization Dependent Extended X-Ray Absorption Fine Structure. J. Phys. Chem. B 2003, 107, 4597-4606.

(43) Bonino, F.; Chavan, S.; Vitillo, J. G.; Groppo, E.; Agostini, G.; Lamberti, C.; Dietzel, P. D. C.; Prestipino, C.; Bordiga, S. Local Structure of CPO-27-Ni Metallorganic Framework upon Dehydration and Coordination of NO. Chem. Mater. 2008, 20, 4957-4968.

(44) Borfecchia, E.; Maurelli, S.; Gianolio, D.; Groppo, E.; Chiesa, M.; Bonino, F.; Lamberti, C. Insights into Adsorption of $\mathrm{NH}_{3}$ on HKUST-1 Metal-Organic Framework: A Multitechnique Approach. J. Phys. Chem. C 2012, 116, 19839-19850.

(45) Benton, A. J.; Drew, M. G. B.; Hobson, R. J.; Rice, D. A. Preparation, Properties, and Crystal and Molecular Structures of the Cyanomethane Adducts of Niobium(IV) Chloride and Di- $\mu$ Sulphido-bis[dichloroniobium(IV)]. J. Chem. Soc., Dalton Trans. 1981, No. 6, 1304-1309.

(46) Cotton, F. A.; Roth, W. J. A Metal-Metal-Bonded Dinuclear Phosphine Complex of Niobium(IV) Chloride, $\left[\mathrm{NbCl}_{2}\left(\mathrm{PMe}_{2} \mathrm{Ph}\right)_{2}\right]_{2}-$ $(\mu \text {-Cl })_{4}$. Inorg. Chem. 1984, 23, 945-947.

(47) Boyd, P. D. W.; Nielson, A. J.; Rickard, C. E. F. Trimethylphosphine Complexes of Niobium(IV) and Tantalum(IV). Crystal, Molecular, and Electronic Structures of $\left[\mathrm{M}_{2} \mathrm{Cl}_{4}(\mu-\mathrm{Cl})_{4}\right.$ $\left.\left(\mathrm{PMe}_{3}\right)_{4}\right](\mathrm{M}=\mathrm{Nb}$ or Ta $)$. J. Chem. Soc., Dalton Trans. 1987, No. 2, 307-314.

(48) Messerle, L. Metal-Metal Bonded Dinuclear and Organodimetallic Complexes of the Early Transition Metals (Groups 4 and 5): Synthesis, Structure, and Reactivity. Chem. Rev. 1988, 88, 12291254.

(49) Canich, J. A. M.; Cotton, F. A. Phosphorus Versus Nitrogen Donor Ligands in Edge-Sharing Bioctahedra of Niobium and Tantalum $\mathrm{M}_{2} \mathrm{Cl}_{6}(\mathrm{~L}-\mathrm{L})_{2}$ Complexes. Inorg. Chem. 1987, 26, 42364240 .

(50) Kakeya, M.; Fujihara, T.; Nagasawa, A. Di- $\mu$-chloro-bis[diacetonitriledichloroniobium(III)] Acetonitrile Disolvate. Acta Crystallogr., Sect. E: Struct. Rep. Online 2004, 60, m893-m894. 
(51) Cotton, F. A.; Roth, W. J. Preparation and Structure of Bis[bis(diphenylphosphino)methane] hexachlorodiniobium(III), $\mathrm{Nb}_{2} \mathrm{Cl}_{6}(\mathrm{dppm})_{2}$. Inorg. Chem. 1983, 22, 3654-3656.

(52) Cotton, F. A.; Roth, W. J. Structural Characterization of a Doubly-Bonded Diniobium Compound, Bis-(1,2-bis-diphenylphosphinoethane)hexachlorodiniobium(III). Inorg. Chim. Acta 1983, 71, $175-178$.

(53) Templeton, J. L.; Dorman, W. C.; Clardy, J. C.; McCarley, R. E. Synthesis and Characterization of New Metal-Metal Bonded Species. 2. Crystal and Molecular Structure of Dimeric Niobium(III) and Tantalum(III) Bromide Adducts with Tetrahydrothiophene. Direct Stereochemical Evidence of Bonding Electron Density in Confacial Bioctahedra with Metal-Metal Double Bonds. Inorg. Chem. 1978, 17, 1263-1267.

(54) Canich, J. A. M.; Cotton, F. A. Structural and Theoretical Considerations in Tantalum and Niobium $\mathrm{M}_{2} \mathrm{Cl}_{6}\left(\mathrm{SMe}_{2}\right)_{4}$ and $\mathrm{M}_{2} \mathrm{Cl}_{6}$ (dto) $)_{2}$ Complexes. Inorg. Chem. 1987, 26, 3473-3478.

(55) Cotton, F. A.; Duraj, S. A.; Falvello, L. L.; Roth, W. J. Vanadium(II) and Niobium(III) Edge-Sharing Bioctahedral Complexes That Contain Bis(dimethylphosphino)methane Bridges. Inorg. Chem. 1985, 24, 4389-4393.

(56) Mathon, O.; Beteva, A.; Borrel, J.; Bugnazet, D.; Gatla, S.; Hino, R.; Kantor, I.; Mairs, T.; Munoz, M.; Pasternak, S.; Perrin, F.; Pascarelli, S. The Time-Resolved and Extreme Conditions XAS (TEXAS) Facility at the European Synchrotron Radiation Facility: The General-Purpose EXAFS Bending-Magnet Beamline BM23. J. Synchrotron Radiat. 2015, 22, 1548-1554. 